\title{
REGULATIONS UNDER THE HIGHER EDUCATION AMENDMENTS OF 1992: A CASE STUDY IN NEGOTIATED RULEMAKING
}

\author{
MARK L. PELESH“ \\ I \\ INTRODUCTION
}

In 1992, Congress reauthorized the student financial assistance programs of the Higher Education Act of 1965 (the "HEA"). ${ }^{1}$ This "reauthorization"-the Higher Education Amendments of 1992 (the "HEA Amendments") ${ }^{2}$-for the first time formally provided for a "Program Integrity Triad" of accrediting agencies, the states, and the Department of Education (the "Department") to control access, or "gatekeeping," to those programs. Congress also mandated that regulations to implement the Program Integrity Triad and other provisions of the legislation be developed through negotiated rulemaking.

This article will review the negotiated rulemaking process used by the Department of Education and its effect on regulations affecting accreditation. Part II will summarize the legislation. Part III will explain the concept of negotiated rulemaking and its accepted attributes. Part III will also describe the Department's efforts to conduct negotiated rulemaking and assess the success or failure of those efforts. Part IV will examine the effect of the process on the regulatory product that resulted.

II

THE HEA AMENDMENTS

\section{A. Program Integrity Triad}

Although accreditation by an agency recognized by the Secretary of Education (the "Secretary"), licensure by the state, and certification by the Department have long been conditions of institutional eligibility to participate in the student financial assistance programs, high default rates and abusive practices of some institutions of higher education impelled Congress in the HEA

\footnotetext{
Copyright (c) 1995 by Law and Contemporary Problems

* Partner, Cohn and Marks, Washington, D.C. Mr. Pelesh was a negotiator for an institutional accrediting agency in the negotiated rulemakings described in this article.

1. Pub. L. No. 89-329, 79 Stat. 1219 (codified as amended in scattered sections of 20 U.S.C.).

2. Pub. L. No. 102-325, 106 Stat. 448 (codified in scattered sections of 20 U.S.C.).
} 
Amendments to specify in much greater detail the gatekeeping responsibilities of each leg of this Triad. ${ }^{3}$ Where previously the HEA provided only that the Secretary was to publish a list of accrediting agencies deemed to be "reliable authority as to the quality of training offered," section 496 of the HEA now sets forth in detail the requirements that an accrediting agency must meet if it is to be recognized by the Secretary. ${ }^{4}$ These requirements concern the agency's structure, accrediting standards, and operating procedures. The statute also addresses the process by which an agency seeks and maintains its recognition.

Structurally, the most noteworthy new requirement is that institutional accreditors be administratively and financially "separate and independent" from related trade associations. ${ }^{5}$ In order to fulfill this requirement, an agency must show that its members are not elected or selected by the board or chief executive officer of the affiliated association, that the agency has one public member for each six members, that dues to the agency are paid separately from dues to the association, and that the agency's budget is independently determined. ${ }^{6}$

The HEA Amendments specify twelve areas that an agency's accrediting standards must assess. Many of these topics are commonly addressed in accrediting standards-curriculum, faculty, and facilities, for example. Other areas would require accrediting agencies to break new ground: They would be required to assess program length, tuition and fees, completion and placement rates, default rates, and compliance with Title IV of the HEA.?

Accrediting agencies must demonstrate that they perform regular site visits to all institutions of higher education and unannounced visits to institutions providing vocational education and training. ${ }^{8}$ They must require institutions to submit business plans when new branches are established, and they must visit these branches within six months of their establishment." The agency is obliged to apply procedures that "comply with due process," including "adequate specification of requirements and deficiencies," "notice of an opportunity for a hearing," a "right to appeal any adverse action," and a "right to representation by counsel." 10 Civil actions challenging accreditation decisions must be brought in federal district court. ${ }^{11}$ The HEA Amendments also mandate significant new disclosure obligations: First, agencies must notify the Secretary and the states within thirty days of actions adverse to institutions, including

3. See Secretary's Procedures and Criteria for Recognition of Accrediting Agencies, 59 Fed. Reg. 3,579 (1994) (to be codified at 34 C.F.R. pt. 602) (proposed Jan. 24, 1994).

4. Compare HEA, Title IV, Part D, § 461, 79 Stat. at 1269, with HEA Amendments, 8499,106 Stat. at 641 .

5. 20 U.S.C.A. § 1099b(a)(3)(A) (West Supp. 1994).

6. Id. \&1099b(b).

7. Id. $\S 1099 \mathrm{~b}(\mathrm{a})(5) ; 42$ U.S.C.A. $\$ \S 2751-2756 \mathrm{a}$ (West Supp. 1994) (establishing the terms and conditions for the student financial assistance program).

8. 20 U.S.C.A. \& $1099 \mathrm{~b}(\mathrm{c})(1)$.

9. Id. \&1099b(c)(2), (3).

10. Id. \&1099b(a)(6).

11. Id. \& $1099 \mathrm{~b}(\mathrm{f})$. 
probation, and second, agencies must provide the Secretary, the state, and the public with a summary of any review that results in an adverse action as well the institution's comments regarding that review. ${ }^{12}$

Although the HEA Amendments call for the Secretary to provide procedures for recognition, ${ }^{13}$ it specifies a number of the elements of the recognition process. The Secretary is prohibited from establishing recognition standards other than those required by the HEA Amendments. ${ }^{14}$ The Secretary is to make an "independent evaluation" of whether the agency has met the criteria for recognition. ${ }^{15}$ In making this evaluation, the Secretary is to make site visits, unannounced as well as announced, and consider third-party information, complaints, and legal actions against the accrediting agency. ${ }^{16}$ The Secretary may also limit, suspend, or terminate an agency's recognition after notice and opportunity for a hearing. ${ }^{17}$

The statutory provisions on the state leg of the Triad are also pertinent to the role of accrediting agencies under the HEA. Section 494 of the HEA Amendments creates a new state postsecondary review program ("SPRP") funded by the federal government. ${ }^{18}$ Under this program, each state designates a state postsecondary review entity ("SPRE"), to conduct reviews of institutions that meet certain criteria, such as default rates above minimum thresholds, in order to determine continued eligibility to participate in the student aid programs. ${ }^{19}$ The SPREs apply review standards that overlap in many respects with accrediting standards. ${ }^{20}$ When an institution comes up for review, however, the SPRE must contract with "the appropriate approved accrediting agency ... or another peer review system" to assess the "quality and content of the institution's courses or programs of instruction, training, or study."21

The provisions on accrediting agency recognition and the SPRP are the product of a legislative compromise. An early version of the House reauthorization bill would have eliminated the role of accrediting agencies as gatekeepers to the student aid programs, substituting expanded state oversight in their place. ${ }^{22}$ Ultimately, accreditation was retained as a requirement of eligibility. However, the requirements for recognition expanded as described above, and the increased state role remained. ${ }^{23}$ While the SPREs' role as gatekeeper is limited to the exit gate from the student aid programs, it is not difficult to

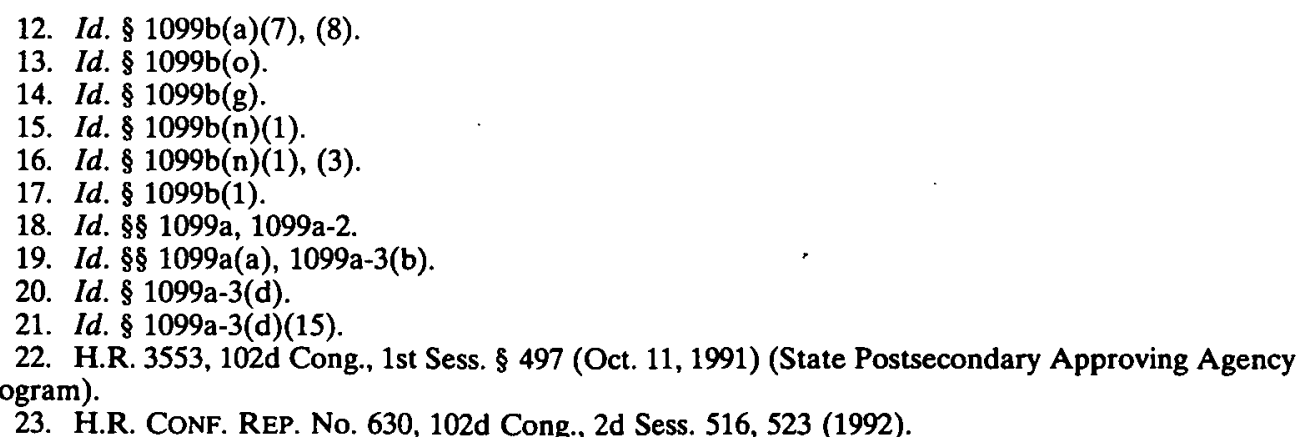

23. H.R. Conf. ReP. No. 630, 102d Cong., 2d Sess. 516, 523 (1992). 
envision circumstances under which that role would grow to include accrediting agencies' control over the entrance and exit gates, thereby rendering the role of accrediting agencies superfluous. As explained below, this possibility proved to have a substantial effect upon the negotiated rulemaking and the resulting regulations.

\section{B. Negotiated Rulemaking Requirement}

The HEA Amendments also specified how the Department was to develop implementing regulations for the recognition of accrediting agencies and the SPRP. The Department was required to convene regional meetings to obtain public input on the formulation of proposed regulations. ${ }^{24}$ After analyzing the information provided at those meetings, the Department was to prepare an initial draft of implementing regulations and "submit such regulations to a negotiated rulemaking process." 25

The HEA Amendments provided guidance on this process. The Department was directed to follow the Recommendations of the Administrative Conference of the United States on procedures for negotiating proposed regulations. ${ }^{26}$ Participants in the negotiations were to be selected from individuals nominated by groups that attended the regional meetings. To the extent possible, the negotiators were to represent the diversity of higher education. ${ }^{27}$ The Federal Advisory Committee Act was declared inapplicable to the regional meetings and the negotiated rulemaking. ${ }^{28}$ Final regulations were required to be issued within 240 days of the enactment of the legislation-that is, by March 23, 1993 - unless unforeseen circumstances compelled the Secretary to adhere to a different schedule. ${ }^{29}$

\section{III}

\section{Negotiated Rulemaking Process}

\section{A. Concept of Negotiated Rulemaking}

The problems associated with traditional notice and comment rulemaking in controversial areas affecting important interests are well known. ${ }^{30}$ The rulemaking process is frequently time-consuming and costly. Participants, with deeply held views or critical interests at stake, often take extreme positions and

24. 20 U.S.C.A. $\$ 1098$ a(a) (West Supp. 1994).

25. Id. \& $1098 \mathrm{a}$ (b).

26. Id. (citing recommendations codified at 1 C.F.R. $\$ \S 305.82-4,305.85-5(1994)$ ).

27. $l d$.

28. Id. \& 1098a(c). This expedited the formation of the negotiating groups and eliminated the requirement that negotiating sessions be open to the public. DAVID M. PRITZKER AND DEBORAH S. DALTON, AdMINISTRATIVE CONFERENCE OF U.S., NEGOTIATED RULEMAKING SOURCEBOOK 52-55 (1990) [hereinafter NEGOTIATED RULEMAKING SOURCEBOOK].

29. 20 U.S.C.A. §§ $1098 \mathrm{a}(\mathrm{b}), 1232(\mathrm{~g})$.

30. See Lawrence Susskind \& Gerard McMahon, The Theory and Practice of Negotiated Rulemaking, 3 YALE J. REG. 133 (1985). 
engage in adversarial conduct. Confronted with this behavior, administrative agencies move cautiously or not at all. When the regulatory result fails to satisfy one or more interest groups, as it almost always does, the regulations are challenged in the courts. Judicial invalidation or suspension of regulations can further protract the regulatory process. The quality of the rules that result from traditional rulemaking is often suspect. ${ }^{31}$

The concept of negotiated rulemaking was proposed by Philip Harter in a seminal article in 1982 as a potential solution to the problems associated with traditional rulemaking. ${ }^{32}$ The central notion underlying the concept is that direct negotiations among the administrative agency and the diverse interests affected by proposed regulations can lead to the more efficient development of final rules and a greater likelihood of consensus for them. Negotiated rulemaking was never intended to be a panacea; if the process were improperly implemented, it could lead to abuse or simply add another layer to an already protracted rulemaking process. ${ }^{33}$

A reasonably settled set of requirements and conditions for success in negotiated rulemaking has now been determined. Indeed, the Recommendations of the Administrative Conference, cited in the HEA Amendments, embody those requirements and conditions. ${ }^{34}$ The Departments of Transportation, Labor, Interior, and Agriculture, the Environmental Protection Agency, the Federal Trade Commission, and the Nuclear Regulatory Commission have used negotiated rulemaking to develop regulations. Of these, the Environmental Protection Agency has the most experience with the process. ${ }^{35}$

In "classic" negotiated rulemaking, the administrative agency engages a convener who prepares a feasibility report. ${ }^{36}$ The convener identifies and interviews interested parties, including the regulatory body, ${ }^{37}$ and forms a prognosis for the negotiated rulemaking and a recommendation on whether to proceed. $^{38}$ If the agency proceeds with the process, it invites representatives of identified interest groups to an organizational meeting. ${ }^{39}$ At this meeting, the parties attempt to agree upon a mission statement, the organizations that will be members of the negotiating committee, and protocols by which the

31. Id. at 133-38.

32. Philip J. Harter, Negotiating Regulations: $A$ Cure for Malaise, 71 GEo. L.J. 1 (1982).

33. See id. at $99-100,110-13$.

34. ADMINISTRATIVE CONFERENCE OF U.S., 1985 RECOMMENDATIONS AND REPORTS 23 (1985) (Recommendation 85-5, Procedures for Negotiating Proposed Regulations) [hereinafter 1985 PROCEDURES]; ADMINISTRATIVE CONFERENCE OF U.S., 1982 RECOMMENDATIONS AND REPORTS 21 (1982) (Recommendation 82-4, Procedures for Negotiating Proposed Regulations) [hereinafter 1982 PROCEDURES]. Curiously, Congress did not cite the Negotiated Rulemaking Act, 5 U.S.C. $\$ \S 581-590$ (Supp. III 1991). Other sources of negotiated rulemaking precepts include NEGOTIATED RULEMAKING SOURCEBOOK, supra note 28; Susskind \& McMahon, supra note 30, at 133.

35. NEGOTIATED RULEMAKING SOURCEBOOK; supra note 28, at 327-43.

36. 1982 PROCEDURES, supra note 34, at 23.

37. NEGOTIATED RULEMAKING SOURCEBOOK, supra note 28 , at 97.

38. Id. at 100; 1982 PROCEDURES, supra note 34, at 24.

39. 1982 PROCEDURES, supra note 34 , at 24. 
committee will conduct itself. ${ }^{40}$ If these agreements are reached, the committee, not the agency, then controls the negotiating process.

The usual goal of such a committee is the actual preparation of proposed regulations along with an explanatory rationale for publication in the Federal Register. $^{41}$ The regulatory agency agrees to publish the product of the negotiating committee's work as a notice of proposed rulemaking ("NPRM"), and the interested parties represented on the committee agree not to comment adversely upon or challenge legally the proposed rules. ${ }^{42}$ This requires all parties, including the regulatory body, to be represented at the negotiating table by persons of sufficient authority to commit the party they represent. ${ }^{43}$ Typically, the negotiating committee operates by consensus, usually defined as the absence of dissent by any member. Under this distinction, no party may be outvoted, but the failure to express disagreement is presumed to mean consent. $^{44}$ In addition, all agreements are presumed to be tentative until full agreement on the regulatory package is reached. If no consensus can be reached, the regulatory agency retains the discretion to propose its own rules. ${ }^{45}$

The negotiations themselves usually occur in discrete sessions, with intervening periods for the parties to caucus. Work groups may be formed to address particular issues or to prepare proposals for the committee as a whole to consider. ${ }^{46}$ The regulatory agency may have the particular role of helping to frame proposals in accepted regulatory language. During the negotiations phase of the process, however, the regulatory agency is merely one of the interested parties. ${ }^{47}$

The potential advantages of negotiated rulemaking are substantial. It engages interested parties, who usually can be readily identified in advance, directly and immediately in the process. It allows these parties to focus on their interests, rather than their positions, which in turn encourages trade-offs. By involving them in the details of the development of regulations, the process wins their support for the regulatory product because it is their product. Negotiated rulemaking diminishes the likelihood of adversarial conduct and later legal challenges, and it builds legitimacy for the results. By "frontloading" dispute into the negotiating committee, the process also reduces the time and cost of promulgating final rules.

Inherent in the model described above are a number of conditions for the success of negotiated rulemaking. There must be a balance of power among the

40. NegOtIATED RULEMAKING SOURCEBOOK, supra note 28, at 177-78.

41. 1982 PROCEDURES, supra note 34, at 25; 1985 PROCEDURES, supra note 34, at 26.

42. NEGOTIATED RULEMAKING SOURCEBOOK, supra note 28 , at 99.

43. Id. at 39; 1982 PROCEDURES, supra note 34, at 24 (recommending that agencies send a senior official to negotiations).

44. NEGOTIATED RULEMAKING SOURCEBOOK, supra note 28, at 178.

45. See 1982 PROCEDURES, supra note 34 , at 25 .

46. NegOtiATEd RULEMAKING SOURCEBOOK, supra note 28, at 179-80.

47. Philip J. Harter, Experienced Practitioner Offers Guidance to Participants in Negotiated Rulemaking, 2 ALTERNATIVE DISPUTE RESOLUTION REP. 80-86 (1988). 
parties, including the regulatory agency, such that negotiation and agreement are better than "BATNA"- the best alternative to negotiated agreement. ${ }^{48}$ The number of interested parties must be limited. ${ }^{49}$ The issues must be ripe for resolution, and they must be sufficiently multifarious to allow trade-offs. ${ }^{50}$ There should be opportunity for mutual gain, that is, "win-win" bargaining, and no party should be required to relinquish its fundamental values in order to achieve agreement. ${ }^{51}$. The parties should set a deadline for decision ${ }^{52}$ and should also appoint a neutral mediator to facilitate the negotiations. ${ }^{53}$

An essential ingredient for success that was particularly pertinent to the negotiated rulemaking under the HEA Amendments was the likelihood of implementation of the negotiated agreement. ${ }^{54}$ Since the purpose of the process is to draft regulations rather than simply to provide more advice and consultation to the regulatory agency, it is important that the agency agree to publish the proposed regulations developed by the negotiating committee verbatim in the form of an NPRM. This requires that the negotiators, including the regulatory agency's representatives, have sufficient stature and authority to make acceptance of the negotiated agreements likely. ${ }^{55}$

\section{B. Implementation by the Department of Education}

The Department began its implementation of the negotiated rulemaking required by the HEA Amendments within weeks after President Bush signed the bill in July 1992. In August 1992, the Department invited a wide array of interested parties to submit lists of issues to be addressed in the rulemaking and convened meetings with these groups at its headquarters. ${ }^{56}$

In accordance with the HEA Amendments, the Department then held four regional meetings in San Francisco, New York, Kansas City, and Atlanta in September $1992 .{ }^{57}$ Any interested party could attend these meetings. The meetings, attended by hundreds of participants, were divided into subgroups addressing various topics. Separate sessions were held on accrediting agency recognition and the SPREs. ${ }^{58}$ For each session, the Department appointed a chair and a reporter, and presented a consolidated list of issues developed from

48. Henry H. Perritt, Jr., Administrative Alternative Dispute Resolution: The Development of Negotiated Rulemaking and Other Processes, 14 PEPP. L. REV. 863, 876 (1987).

49. NEgOTIATED RULEMAKING SOURCEBOOK, supra note 28, at 37.

50. Id. at 37-38.

51. See id. at 38 .

52. Id. at 39.

53. Harter, supra note 47, at 80; see also 1985 PROCEDURES, supra note 34, at 26.

54. Harter, supra note 32, at 99-102.

55. Id.; see also 1985 PROCEDURES, supra note 34, at 26; 1982 PROCEDURES, supra note 34, at 24-5; NEgOTIATED RULEMAKING SOURCEBOOK, supra note 28, at 39.

56. Letter from Carolyn Reid-Wallace, Assistant Secretary, Office of Postsecondary Educ., Dep't of Educ., to Kenneth Perrin, President, Council on Postsecondary Accreditation (Aug. 12, 1992) (on file with author).

57. See The Higher Education Amendments of 1992: Notice of Regional Meetings, 57 Fed. Reg. 38,640 (1992).

58. Id. at $38,639-40$. 
the August meetings. Department staff attended the sessions but did not participate. The purpose of the sessions was to obtain the views of the nonfederal parties in attendance on the issues and to determine whether they were in agreement on the resolution of those issues. ${ }^{59}$

Attendees at the regional meetings nominated negotiators in October 1992. The Department selected fifteen negotiators for the accreditation regulations in November 1992. Included were representatives of institutional and programmatic accrediting agencies, institutions of higher education, state higher education offices, and a legal aid group. ${ }^{60}$ The Department prepared an initial draft of the proposed regulations and scheduled the first negotiating sessions for one week in December 1992 and one week in January $1993 .{ }^{61}$ Since the Department had not prepared a draft of the proposed regulations on the SPRP, no negotiators for those sessions were appointed, and a negotiating session on those regulations was not scheduled. Owing to scheduling conflicts, the sessions announced by the Department were postponed to January and February $1993 .^{62}$

A number of parties urged a further postponement in light of the upcoming change of administrations as a result of the 1992 presidential elections. They urged that negotiations would likely be more productive after the new political leadership was in place at the Department. They also argued for postponement because the regulations for each leg of the Program Integrity Triad should be developed in a coordinated manner, and only the accreditation proposals had been drafted. Pointing to the 240-day deadline, however, the remaining leadership from the Bush Administration at the Department declined to suspend the negotiating sessions.

Thus, the Department held negotiating sessions in the first week of January and the first week of February of 1993. ${ }^{63}$ The Department retained professional mediators for each negotiating group and presented proposed organizational protocols at a general meeting of all negotiators on the eve of the first session. The proposed protocols were presented with little background or orientation on their preparation or on negotiated rulemaking, and they elicited substantial criticism and opposition from many of the negotiators. In particular, these negotiators professed to be unable or unwilling to make binding commitments on behalf of the organizations they represented. They also expressed concern

59. Id at 38,639 .

60. See Letter from Carolyn Reid-Wallace, Assistant Secretary, Office of Postsecondary Educ., Dep't. of Educ., to author (Nov. 24, 1992) (on file with author) [hereinafter Reid-Wallace letter]; Memorandum from Robert W. Evans, Director, Division of Policy, Training and Analysis Service, Dep't of Educ., to Negotiators (Nov. 25, 1992) (on file with author).

61. Reid-Wallace letter, supra note 60, at 1-2.

62. Memorandum from Robert W. Evans, Director, Div. of Policy, Training and Analysis Servs., Dep't of Educ., to author (Dec. 1, 1992) (on file with author).

63. The Higher Education Amendments of 1992: Negotiated Rulemaking, 57 Fed. Reg. 62,533-34 (1992). 
that the Department agreed only to use any agreements reached during the negotiations "to the maximum extent possible." ${ }^{4}$

As a result, the Department revised the protocols to eliminate provisions obligating organizations represented by the negotiators not to comment adversely on the regulations eventually presented in an NPRM or to challenge the final regulations in court. For its part, the Department continued to agree only to use any agreements to the maximum extent possible; it would publish an NPRM "consistent with the agreement or explain in the preamble to the NPRM why any changes have been made."65 During the second week of the negotiations, the Department amplified its position: The new Secretary, Richard Riley, informed the negotiators through Department staff that he would review any agreements reached to determine whether they were acceptable. If they were not, he might recall the negotiators for further meetings. If no agreement were reached, the Department would simply make proposals as it saw fit.

The accreditation negotiating sessions themselves quickly became a twosided affair. The nonfederal negotiators, principally the representatives of accrediting agencies and institutions of higher education, presented criticisms of the draft that the Department had prepared, and the Department's representatives, midlevel career civil servants, responded. In many areas, the Department resisted changes to the proposals presented. In some areas, the Department's representatives indicated a willingness to consider alternatives and even to agree to modifications. Subsequently, however, after consultation with other Department officials outside the negotiations, they would often recede from these agreements and adhere to positions the Department had previously taken.

At the conclusion of the second and final week of negotiations in February, consensus had been reached in a limited number of areas that had been at issue when the discussions began in January. ${ }^{66}$ Thereafter, the Department extensively revised the proposed regulations and submitted them to the negotiators in May 1993 for their "technical review and comment."67 Notwithstanding the Department's assurance that it had kept to the substance of any agreements that had been reached, a number of the negotiators disagreed and argued that the revised draft departed substantively from a number of consensus positions that had been achieved. ${ }^{68}$

64. Department of Educ., Draft Organizational Protocols 2-3 (Jan. 3, 1993) (on file with author).

65. Department of Educ., Organizational Protocols 2 (Jan. 6, 1993) (on file with author).

66. See Department of Educ., Draft Part 602, Secretary's Procedures and Criteria for the Recognition of Accrediting Agencies (Feb. 15, 1993) (on file with author).

67. Letter from Carol F. Sperry, Acting Director, Institutional Participation and Oversight Servs., Dep't. of Educ., to author 1 (May 7, 1993) (on file with author).

68. See, e.g., James Rogers, Commission on Colleges of the Southern Association of Colleges and Schools, Comments on Part 602 - Secretary's Procedures and Criteria for the Recognition of Accrediting Agencies (May 17, 1993) (on file with author); Letter from author to Carol F. Sperry. Acting Director, Institutional Participation and Oversight Servs., Dep't. of Educ. (May 17, 1993) (on file with author). 
The SPRE negotiating sessions were held in the last week of April 1993 and the second week of June 1993..$^{6}$ Again, fifteen negotiators were selected, and the composition of the negotiators was much the same. Five of the nonfederal negotiators in the accreditation sessions also served as negotiators in the SPRE sessions. The Department's negotiating team was also similar to its team for the accreditation regulations. As might be expected, state interests were more significantly represented. ${ }^{70}$ The diluted protocols ultimately agreed upon for the earlier accreditation sessions were readily accepted here as well. ${ }^{71}$

Time for discussion of the SPRE regulations was limited because proposed regulations on an unrelated area-admission of ability-to-benefit students-was included in the sessions. The presence of state interests also altered the dynamic of the negotiations somewhat. The Department became more an interested observer to disagreements between the state representatives (who were generally satisfied with the Department's proposals and anxious to implement the SPRP as quickly as possible) and representatives of institutions of higher education and accreditors (who were fearful of state efforts to exercise oversight authority over institutions and to supplant the functions of accrediting agencies). Again, hopes raised by the willingness of Department representatives to consider changes proposed by nonstate, nonfederal negotiators were disappointed after consultations occurred outside the negotiations. The frustrations of these negotiators resulted in a letter to Secretary Riley during the second week of negotiations formally objecting that the Department was not engaging in true negotiated rulemaking. ${ }^{72}$ Although the newly appointed Assistant Secretary for Postsecondary Education urged the negotiators in a special meeting to persevere, no consensus was reached on any material issues in the SPRE negotiations. ${ }^{73}$

An additional impediment throughout the negotiating sessions for both the accreditation and SPRE regulations was the Department's refusal to disclose and negotiate the terms of the preamble-the text providing the background and rationale for the regulations. As the "legislative history" of the regulations, the preamble would obviously be crucial to future understanding and interpretation. The nonfederal negotiators requested that they be provided with the preamble at several points, but the Department's representatives declined to do so during the negotiations. Instead, the preamble became a prospective but unexaminable repository for points ostensibly to satisfy the concerns of nonfederal negotiators.

69. The Higher Education Amendments of 1992: Negotiated Rulemaking, 58 Fed. Reg. 25,590 (1993).

70. Id.

71. Department of Educ., Negotiated Rulemaking Comm. for Part B of the Title IV Higher Education Amendments of 1992, Draft Organizational Protocols (Apr. 25, 1993) (on file with author).

72. Letter from Negotiators to Richard S. Riley, Secretary of Educ. (June 15, 1993) (on file with author).

73. State Postsecondary Review Program, 59 Fed. Reg. 3604, 3605 (1994) (to be codified at 34 C.F.R. \& 667). 


\section{Assessment of the Process}

The negotiated rulemaking conducted by the Department was clearly flawed. It departed extensively from the "classic" model of negotiated rulemaking that has evolved since Mr. Harter's article in 1982, and it failed to follow the precepts set forth in the Administrative Conference's Recommendations as mandated by Congress.

Many of the conditions for successful negotiated rulemaking had been present after the enactment of the HEA Amendments. "BATNA," the best alternative to a negotiated agreement, pointed to negotiations as the preferred way to promulgate regulations. The Department had been singularly unsuccessful in promulgating regulations during the previous reauthorization cycle, and thus it ought to have had an incentive to win the cooperation of the higher education community. ${ }^{74}$ At the same time, the HEA Amendments imposed many new and stringent requirements upon the participants in the student financial assistance programs, and thus they had an incentive to work with the Department to achieve reasonable interpretations of those provisions. There was, therefore, an opportunity to gain through bargaining. Both the Department and the parties represented in the negotiations faced the possibility of severe loss in conventional notice and comment rulemaking.

Although the number of interests affected by the regulations was quite large, the areas for regulation were reasonably discrete. The accreditation regulations involved fifteen negotiators representing roughly five interests. The SPRE regulations involved a similar array of interests. Those interests need not have been irreconcilable. Except to the degree that some may not have conceded the legitimacy of participation in the student aid programs of others, the parties' fundamental values did not necessarily have to be relinquished. ${ }^{75}$.

Other factors were also conducive to successful negotiations. Congress had imposed a deadline which ought to have served as a spur to focused discussions. Access to information was not critical; no party had the ability to influence the negotiations unduly because it controlled crucial information. The mediator chosen for the accreditation and SPRE negotiations was neutral, experienced, and capable.

Yet the negotiation process failed. Relatively little consensus was achieved in the accreditation sessions, and no consensus was achieved in the SPRE sessions. Even with respect to the agreements reached in the accreditation sessions, subsequent revisions provoked substantial protest by nonfederal negotiators.

74. The Department was still promulgating regulations to implement the previous reauthorization legislation when the HEA Amendments were under consideration. See, e.g., Pell Grant Program, 56 Fed. Reg. 56,912-17 (1991).

75. Some representatives of regional accreditors of colleges and universities and the states expressed the view from time to time that the changes necessitated by the HEA Amendments were owing entirely to abuses by proprietary schools and were being unfairly applied to all institutions of higher education. 
Events after the conclusion of the SPRE negotiations in June 1993 confirm the failure of the negotiated rulemaking process. In response to the criticisms levelled at the Department's conduct of the process, it convened a "debriefing" session in September 1993. While the Department stressed that this was not a negotiating meeting, it permitted participants to identify departures from consensus, to request clarification, to identify and discuss pertinent issues not previously raised, and to address overlap issues between sets of regulations, such as the accreditation and SPRE rules. ${ }^{76}$ The Department also finally released a draft of the preamble for the accreditation regulations. ${ }^{77}$ Thus, the September debriefing sought after the fact to resolve dissatisfaction with the rulemaking process.

Throughout the fall and winter, interested parties, including organizations that had been directly or indirectly represented in the negotiated rulemaking, lobbied the Department for changes in the proposed regulations. ${ }^{78}$ Target dates for the publication of NPRMs were repeatedly missed. Obviously, these developments would not have occurred had the negotiated rulemaking been successful.

Finally, on January 24, 1994, ten months after the congressional deadline, NPRMs were published in the Federal Register for the rules on recognition of accrediting agencies and the State Postsecondary Review Program. ${ }^{79}$ Interested parties were allowed to comment until March $21,1994{ }^{80}$ More than 1800 comments were filed on the accreditation proposals, and a similar number were filed on the SPRE proposals. ${ }^{81}$ The vast majority of these comments, including those of parties represented in the negotiated rulemaking, were extremely critical of the proposed rules and the process by which the proposals were developed. If one of the aims of negotiated rulemaking is to "frontload" criticism and thereby reduce the time required to develop regulations, the delay in the issuance of the NPRMs and the response to them show that this aim was not achieved.

76. Letter from David A. Longanecker, Assistant Secretary for Postsecondary Educ., Dep't. of Educ., to "Colleagues" (Sept. 8, 1993) (on file with author).

77. Department of Educ., Draft Part 602, Secretary's Procedures and Criteria for the Recognition of Accrediting Agencies (Sept. 13, 1993) (on file with author). The preamble to the SPRE regulations was not available for review at the debriefing.

78. Jim Zook, College Presidents Lobby Against New Accrediting Regulations, CHRON. HIGHER Educ., Jan. 12, 1994, at A26; Jim Zook, Education Dept. Revises Controversial Draft of Accreditation Regulations, CHRON. Higher EDUC., Jan. 26, 1994, at A36.

79. Secretary's Procedures and Criteria for Recognition of Accrediting Agencies, 59 Fed. Reg. 3578 (1994) (to be codified at 34 C.F.R. \& 602) (notice of proposed rulemaking Jan. 24, 1994) [hereinafter Accreditation NPRM]; State Postsecondary Review Program, 59 Fed. Reg. 3604 (to be codified at 34 C.F.R. \& 667) (notice of proposed rulemaking Jan. 24, 1994) [hereinafter SPRE NPRM].

80. Accreditation NPRM, supra note 79, at 3578; SPRE NPRM, supra note 79, at 3604.

81. Secretary's Procedures and Criteria for Recognition of Accrediting Agencies, 59 Fed. Reg. 22,250, 22,253 (1994) (to be codified at 34 C.F.R. \$ 602) [hereinafter Accreditation Final Regulations]; State Postsecondary Review Program, 59 Fed. Reg. 22,286, 22,288 (1994) (to be codified at 34 C.F.R. $\S 667$ ) [hereinafter SPRE Final Regulations]. 
The reason for this outcome was the absence of two of the accepted conditions for success of negotiated rulemaking: the authority of the negotiators to make binding commitments and the related likelihood of implementation of agreements reached. At the very outset of the process, many of the nonfederal negotiators disclaimed their authority to make agreements on behalf of the organizations that they represented. For its part, the Department sent to the negotiating table representatives who lacked the power to commit the Department. This lack of authority was demonstrated both by their positions within the Department-they were midlevel officers at most-and by the repeated instances where apparent agreements were reversed after consultations outside the negotiations.

The absence of decisionmakers on both sides of the bargaining table undermined the likelihood of implementation of such agreements as could be made. On the nonfederal side, provisions in the organizational protocols forbidding the filing of adverse comments or legal challenges were stricken. On the Department side, the protocols contemplated that the Department could make changes to agreements since they permitted the Department to "explain in the preamble to the NPRM why any changes have been made." Secretary Riley also indicated that the Department reserved all its rights as to the substance of the regulations.

The Department's decision to move forward with the process despite the change of administrations and its failure to structure the process more in keeping with the "classic" model of negotiated rulemaking largely account for these deficiencies. Department representatives were unable to commit the Department because its political leadership was in flux or absent. The first draft of the accreditation regulations, for example, reflected the policy preferences of a lame duck administration whose leaders were gone by the time the first negotiating session began. Those leaders obviously could not sit at the negotiating table, and the midlevel officials who actually were present could only guess at the policy wishes of new leaders not yet chosen.

While Secretary Riley was quickly installed, he could not reasonably have been expected to negotiate or even be conversant with the details of the regulatory package so quickly. The critical decisionmaker was the Assistant Secretary for Postsecondary Education in whose office responsibility for the student aid programs lay. That post was not filled until June 1993-at the very conclusion of the SPRE negotiations and months after the accreditation negotiations.

It must be acknowledged that the inability of some of the nonfederal negotiators to commit their organizations contributed to the failure of the process. The Department's structuring decisions for the negotiations, however, were primarily responsible for the positions these parties took. Rather than involve the nonfederal parties in the selection of the mediators and especially the preparation of the organizational protocols, the Department simply presented them in a large group meeting with a sense of fait accompli on the 
eve of the first negotiating session. Lacking any orientation to the concept of negotiated rulemaking or knowledge about the matters to which they were being asked to give assent, these negotiators understandably pulled back from surrendering rights that previous experience with the Department suggested might be important. ${ }^{82}$

The negotiating sessions themselves exacerbated the difficulties. Instead of numerous, relatively brief sessions with opportunities to caucus so that constituents could be consulted and issues could be worked out over time, the sessions were limited to two intensive weeklong sessions that predictably left many issues unresolved. Further, by controlling and principally defending the text of the proposed regulations, the Department assumed a dominant position and was not just one of the negotiating parties. Its decision to withhold the preamble and not to negotiate all of the Program Integrity Triad provisions in a coordinated manner added to a sense that it was unwilling to give up any real control of the regulatory product.

The Department's rejoinder to these objections, which were made from time to time by some parties, was that the 240-day congressional deadline made the approach that it had chosen necessary. Yet events robbed this point of any force that it might have ever had. Most obviously, the Department did not meet the deadline. Six months after it, the Department was convening a debriefing to offer palliatives for the objections of the participants. It did not publish NPRMs until four months after the debriefing, and it did not promulgate final regulations for more than a year after the end of the 240-day period specified by Congress. Thus, there clearly was an opportunity for more adequate preparation and negotiating sessions consistent with the generally accepted model of negotiated rulemaking. And, in any event, the 240-day requirement left the Secretary the latitude to extend the schedule for good cause, an option that he must have exercised in view of the failure to meet the deadline.

In sum, the Department did have the ability to engage the parties more deeply in the process, thereby winning a greater contribution and commitment to the regulatory product. It chose not to do so, it would appear, because of a desire to create the impression of progress in accordance with perceived congressional wishes. In so doing, it created only the facade of negotiated rulemaking.

82. The Administrative Conference and other authorities on negotiated rulemaking suggest such training and orientation before the negotiations begin. 1985 ProCEDURES, supra note 34, at 26; NEGotiated RulEMAKING SOURCEBOOK, supra note 28, at 161-63. 
IV

\section{EFFECT ON REGULATIONS}

\section{A. Accreditation Regulations}

On balance, the negotiated rulemaking had little effect on the regulatory product. The essential themes of the initial draft of proposed accreditation regulations in November 1992 were (1) conversion of accreditation from a peer review to a regulatory/compliance process, (2) reliance on minimum quantitative standards-trip wires-for determining compliance, (3) requirements that accrediting agencies take action when noncompliance is found, (4) greater use of accrediting agencies to assist the Department in the performance of its functions, (5) a two-tier approach to focus more stringent requirements upon agencies accrediting "prebaccalaureate vocational education programs." and (6) more rigor and detail in the recognition process. ${ }^{83}$

Those themes remained in the Accreditation NPRM published in January 1994. Thus, the proposed regulations greatly elaborated on the statutory requirement that accrediting agencies have standards addressing the twelve specified areas and prescribed the content of many accrediting standards. ${ }^{84}$ Agencies would have been required to have standards establishing minimum and maximum program lengths and minimum quantitative standards for completion rates, job placement rates, and pass rates on licensing examinations. ${ }^{85}$ The Accreditation NPRM also suggested that acceptable ratios between tuition and expected earnings. be established. ${ }^{86}$ Further, the proposed regulations would have required accrediting agencies to be notified of and approve in advance additions to or substantive changes in educational programs. $^{87}$ Additionally, when an agency determined that an institution or program was out of compliance with any standard, the agency would have been obliged to take prompt adverse action or to require the institution or program to come into compliance within an eighteen-month period. ${ }^{88}$

The Accreditation NPRM thus reflected the Department's desire to make greater use of accrediting agencies to enforce Title IV of the HEA. In addition to the disclosures required by the HEA, the proposed regulations would have required accrediting agencies to provide the Secretary upon request with information to assist in "resolving problems" with accredited institutions. ${ }^{89}$ The NPRM also suggested that agencies be obligated to provide to the

83. Department of Educ., Draft Part 602, Secretary's Procedures and Criteria for the Recognition of Accrediting Agencies (Nov. 10, 1992) (on file with author).

84. Accreditation NPRM, supra note 79 , at 3597-98.

85. Id.

86. Id. at $3586-87$.

87. Id. at 3597.

88. Id at 3588 .

89. Id. at 3593. 
Inspector General all instances of "fraudulent activities." substantive changes, minimum quantitative standards, and unannounced visits to institutions offering vocational education were limited in the Accreditation NPRM to prebaccalaureate vocational education programs because abuses have purportedly been centered in those programs. ${ }^{11}$

The Accreditation NPRM proposed procedures for recognition in considerable detail. In this area, the negotiations did have some impact. The right of an agency to respond to adverse findings and negative comments was incorporated as was the right to proceedings on the record. ${ }^{92}$ The proposed regulations further provided for the statement of the basis for any adverse decisions and some semblance of an appeal. ${ }^{93}$ All of these basic procedural protections were lacking when the negotiated rulemaking began. ${ }^{94}$

On April 29, 1994, the Department published final regulations for the recognition of accrediting agencies. In contrast to the negotiated rulemaking, the notice and comment process appeared to have had a substantial effect on the regulatory product. All elaboration of the statutory topics which accrediting standards must address . was eliminated. ${ }^{95}$ Requirements for quantitative standards, or "trip wires," for completion, placement, pass rates on licensing examinations, and tuition and fees were deleted. ${ }^{96}$ The final regulations also excised the "prebaccalaureate vocational education" concept." "The commentary accompanying the final regulations rejected the proposition that abuses have predominated at vocational institutions and stated that the regulations should apply evenly to all sectors of higher education. ${ }^{98}$ These were all significant modifications to aspects of the regulations that had been present throughout the rulemaking process.

Nonetheless, the final regulations continued in important respects to confirm the conversion of accreditation from a collegial, peer review process to an administrative, regulatory process. The requirement for prior approval of new and substantially different programs remained in the final regulations. ${ }^{99}$ Requirements that accrediting agencies provide information to assist the Secretary in "resolving problems" and on "fraud and abuse" at institutions were also retained. ${ }^{100}$ Even in the area of accrediting standards, the commentary to the regulations stated that, in setting standards, accrediting agencies were to take into account, and not set standards lower than, federal and state standards

90. Id. at 3581 .

91. Id. at $3580,3584,3586,3587$.

92. Id. at 3593-94.

93. Id.

94. See Department of Educ., Draft Part 602, Secretary's Procedures and Criteria for the Recognition of Accrediting Agencies 3-6 (Nov. 10, 1992) (on file with author).

95. Accreditation Final Regulations, supra note 81, at 22,260.

96. Id.

97. Id. at 22,252 .

98. Id. at 22,264 .

99. Id. at $22,259-60$.

100. Id. at 22,255 . 
in comparable areas. ${ }^{101}$ The final regulations and accompanying commentary heavily emphasized the concept of accountability-if accrediting agencies do not adopt and enforce rigorous standards or if the performance of their accredited institutions is poor, the Department will remove recognition. ${ }^{102}$

\section{B. State Postsecondary Review Entity Regulations}

From an accreditor's perspective, the SPRE regulations were highly resistant to change throughout the process. The principal features in the initial draft in April 1993 were as follows: (1) ceding to the states the discretion to choose whether to contract with accrediting agencies or "peer review systems" of unknown provenance and refusal to require such peer review systems to be subject to Departmental review and approval; (2) refusal to provide for interested party input on items to be submitted to the Department for review and approval, such as state review standards, plans and budgets for review, and funding applications; (3) minimum quantitative standards for completion, placement, and pass rates, and acceptable percentages for the relationship between tuition and fees and expected remuneration; (4) latitude for different standards for different types of institutions; and (5) refusal to permit the states the right to choose not to participate in the SPRP without institutions in the state incurring sanctions specified in the statute. ${ }^{103}$

The SPRE NPRM contained all of these elements. The proposed regulations left to the states the determination whether to use a recognized accrediting agency or a peer review system to perform the quality review mandated by the statute. ${ }^{104}$ It also left to the SPRE the evaluation of the qualifications of such peer review systems. ${ }^{105}$ The SPRE NPRM did somewhat grudgingly note and request comment on accreditors' proposals that the Secretary define "peer review system" and specify criteria to determine the competence of these systems, but it indicated a disinclination to preserve much of a role for accrediting agencies in this area. ${ }^{106}$

The SPRE NPRM made no provision for interested party review and comment upon the various state submissions to the Department required under the HEA Amendments and the proposed regulations. ${ }^{107}$ During the negotiated rulemaking, both the Department's representatives and state representatives rejected any such proposals from accreditors and institutions of higher education because they believed these procedures would unduly delay the implementation of the SPRE program.

101. Id. at 22,251 .

102. Id. at $22,250,22,263,22,271$.

103. Department of Educ., Draft Notice of Proposed Rulemaking, Part 667, State Postsecondary Review Program (Apr. 16, 1993) (on file with author) [hereinafter Draft Notice].

104. SPRE NPRM, supra note 79 , at $3621-22$.

105. Id.

106. Id. at $3614-15$.

107. See id. at $3619-22$. 
The SPRE NPRM also reflected some movement on the use of quantitative measures in the criteria for state review standards. The initial draft of the regulations presented to the negotiators was highly detailed on this score and proposed specific trip wires for determining when an institution being reviewed would be deemed out of compliance. ${ }^{108}$. These specific tests were criticized by all nonfederal negotiators, including state representatives. The Department dropped them in the SPRE NPRM but still proposed that state review standards on outcomes and tuition and fees be quantified. ${ }^{109}$

The latitude of the SPREs to create differential standards actually broadened throughout the process. The initial draft of the regulations did not specifically so provide. ${ }^{110}$ When the initially proposed trip wires were eliminated, the draft was revised to permit this possibility. ${ }^{111}$ Further, the SPRE NPRM proposed to restrict the definition of "vocational program," which limits the applicability and effect of the placement standard, to the prebaccalaureate level. ${ }^{112}$. Finally, the SPRE NPRM, like all drafts of the proposed regulations, refused to recognize the right of a state to decline to participate in the SPRE program. ${ }^{113}$ The Department's refusal again reflected a desire to implement the SPRE program as widely as possible. ${ }^{114}$

The final regulations for the SPRE program were also published on April 29,1994 . The Department made few changes to the proposals presented in the SPRE NPRM. Although it specified some minimal criteria for the selection of other "peer review systems," the Department left to the states the choice of whether to use these systems or recognized accrediting agencies. ${ }^{115}$ The Department also rejected as unduly burdensome proposals to allow third parties to review and comment upon state review standards, review plans and budgets, and applications for funds. ${ }^{116}$ Further, the final regulations retained minimum quantitative standards for outcomes and the provision permitting different

108. For example, the initial proposed regulations provided for a minimum completion rate of $67 \%$, a minimum placement rate of $70 \%$, and a minimum pass rate on licensing examinations of $80 \%$. Draft Notice, supra note 103, at 24-25.

109. SPRE NPRM, supra note 79 , at 3621.

110. See Draft Notice, supra note 103, at 20-27.

111. Department of Educ., Draft Part 667, State Postsecondary Review Program 31 (Sept. 13, 1993) (on file with author).

112. SPRE NPRM, supra note 79 , at 3606 .

113. Id. at 3617. This right turns upon the admittedly fine distinction in the statute between a state that "declines" and a state that "fails" to enter into an agreement with the Secretary to carry out the program. Compare 20 U.S.C.A. \$ 1099a(b) (West Supp. 1994) with id. \& 1099a(c). In the latter case, the statute imposes severe penalties on institutions in the state. Id. Representatives of institutions of higher education, in particular, had contended that a state could decline to participate without these penalties becoming applicable.

114. Indeed, the Department and the states implemented many aspects of the SPRE program before the SPRE NPRM was even published. See Department of Educ., State Postsecondary Program Status Report (Jan. 1994) (on file with author) (chart of states, SPRE designations, receipt and approval of agreements and plans); accord SPRE NPRM, supra note 79, at 3610.

115. SPRE Final Regulations, supra note 81, at 22,297.

116. Id. at 22,309 . 
standards for different types of institutions. ${ }^{117}$ Finally, the regulations failed to recognize the right of a state to decide not to participate in the SPRE program. ${ }^{118}$

In general, the Department elected to defer substantially to the states. The final regulations and accompanying commentary were filled with expressions of trust in the states' proper implementation of the SPRE program and refusals to adopt provisions that would limit their discretion or hold them accountable. ${ }^{119}$ In contrast to the accrediting agency recognition regulations, the SPRE regulations contained no provisions to measure SPRE performance. ${ }^{120}$

\section{CONCLUSION}

The notice and comment phase of the rulemaking on the regulations affecting accreditation confirmed the failure of the negotiated rulemaking. Accrediting agencies, institutions of higher education, and higher education associations all heavily criticized the proposals presented in the NPRMs, and these criticisms had some effect. However, if one of the aims of negotiated rulemaking is to frontload criticism and avoid later adversarial conduct and expenditure of resources, these developments clearly showed that the process did not succeed here.

If properly implemented, the negotiated rulemaking could have had a substantively beneficial effect. Concededly, many aspects of the proposed regulations were compelled by statute. Required accrediting standards, unannounced visits, and broader disclosure requirements were all mandated in some detail by Congress. Similarly, the enhanced role of the states, triggers for SPRE review, and the state review standards were spelled out in the HEA Amendments with considerable specificity.

Nevertheless, the Department's fundamental refusal to cede any real control of the regulatory process, coupled with ill-advised administrative decisions during the transition from the Bush to the Clinton Administrations, resulted in two sets of regulations that pushed the "governmentalization" of control of access to the student aid programs materially farther than that specified by Congress. By permitting a genuine exchange of views and trade-offs between accreditors and institutions on the one hand and federal and state governments on the other, a true negotiated rulemaking would have recognized the continued vitality and need for a nongovernmental role in the administration of these programs. In turn, accrediting agencies and accredited institutions might have come to accept more fully the legitimate demands for accountability of students, their families, and government. Instead, the process was effectively transmuted

117. Id. at 22,295 .

118. Id. at 22,290 .

119. E.g., id. at 22,300, 22,302-06, 22,311.

120. Id. at 22,310 . 
into a more elaborate version of notice and comment rulemaking, with its concomitant adversarial conduct, time, cost, and, most importantly, resistance to the legitimacy of its results. Negotiated rulemaking under the HEA Amendments was a missed opportunity. 